\title{
ANALYZING THE DETERMINANTS OF E-COMMERCE IN SMALL AND MEDIUM-SIZED ENTERPRISES: A COGNITION-DRIVEN FRAMEWORK
}

\author{
Ricardo M. R. BARROSO ${ }^{1}$, Fernando A. F. FERREIRA ${ }^{1,2^{*}}$, \\ Ieva MEIDUTE்-KAVALIAUSKIENE் $\dot{E}^{1,3}$, Nerija BANAITIENE ${ }^{4}$, \\ Pedro F. FALCÃO ${ }^{1}$, Álvaro A. ROSA ${ }^{1}$ \\ ${ }^{1}$ ISCTE Business School, BRU-IUL, University Institute of Lisbon, \\ Avenida das Forças Armadas, 1649-026, Lisbon, Portugal \\ ${ }^{2}$ Fogelman College of Business and Economics, University of Memphis, Memphis, \\ TN 38152-3120, USA \\ ${ }^{3}$ Research Centre, General Jonas Žemaitis Military Academy of Lithuania, \\ Šilo g. 5A, Vilnius 10322, Lithuania \\ ${ }^{4}$ Department of Construction Management and Real Estate, Faculty of Civil Engineering, \\ Vilnius Gediminas Technical University, Sauletekio al. 11, Vilnius 10223, Lithuania
}

Received 15 November 2018; accepted 03 February 2019

\begin{abstract}
The increasing use of information technology in enterprises' daily operations has led to multiple innovative ways to run a business, including electronic commerce (hereafter, e-commerce). However, firms with fewer resources, such as small and medium-sized enterprises (SMEs), are more reluctant to use electronic channels during transactions. This aversion to contemporary business models is a result of these companies' lack of knowledge and capabilities regarding e-commerce. To improve their businesses, SMEs' managers and decision makers could benefit from a methodological framework that fosters a deeper understanding of the determinants of e-commerce. This study sought to explore the use of fuzzy cognitive mapping to address this need. The results are grounded in the knowledge and experience of a panel of experts in e-commerce. The fuzzy cognitive map (FCM) developed shows that entrepreneur profile, market, operational management, marketing and promotions, website and digital platform, and products present the highest centrality indices as determinants of SME e-commerce. The findings offer a better understanding of the cause-and-effect relationships between these determinants. The advantages, limitations, and shortcomings of our constructivist proposal are also discussed.
\end{abstract}

Keywords: small and medium-sized enterprises (SMEs), e-commerce, decision support systems, fuzzy cognitive map (FCM).

JEL Classification: C44, C45, M10.

${ }^{*}$ Corresponding author. E-mails: fernando.alberto.ferreira@iscte.pt; fernando.ferreira@memphis.edu 


\section{Introduction}

Small and medium-sized enterprises (SMEs) play a crucial role in contemporary societies. Besides being a significant source of employment, SMEs are responsible for economic development and innovation, family income and well-being, social change, and greater empowerment (Rahayu \& Day, 2015; Castela, F. Ferreira, J. Ferreira, \& Marques, 2018; Grillo, F. Ferreira, Marques, \& J. Ferreira, 2018). However, as Savrul, Incekara, and Sener (2014) note, this type of firm has great resource limitations that restrain SMEs from successfully competing in a global market.

The adoption of electronic commerce (hereafter, e-commerce) can help overcome some constraints, allowing SMEs to reach international markets (Cegarra-Navarro, Jiménez, \& Martínez-Conesa, 2007; Child et al., 2017). Despite the benefits of e-commerce, a study by the Organization for Economic Cooperation and Development [OECD] (2004) found that SMEs are more reluctant to adopt e-commerce practices than multinational companies are. MacGregor and Vrazalic (2006) state that SMEs' preference for traditional ways of doing business and these firms' limited ability to implement e-commerce practices are both barriers to their adoption of e-commerce.

Ways to promote SMEs' adoption of e-commerce include clarifying the structure of ecommerce and understanding entrepreneurs' beliefs about it. These methods, however, necessitate the incorporation of the perspective of multiple stakeholders and their personal values and expectations, which requires the application of structuring methods capable of dealing with subjective information and uncertain contexts (Cunha \& Morais, 2017). According to Mackenzie et al. (2006), decision makers need to use a substantive rationality approach to deal with extremely complex, poorly structured, and highly dynamic problems.

As Salmeron (2012, p. 3706) states, "real-world challenges are usually characterized by a number of components interrelated in many complex ways". Therefore, problem structuring methods (PSMs) are quite useful when dealing with this type of decision problem for various reasons. First, these methods emphasize the process over the results, using models based on concepts, procedures, and techniques (Vidal, 2004). Second, PSMs consider multiple objectives and perspectives, exploring the problem from a holistic perspective (Belton, Ackermann, \& Shepherd, 1997). Last, these methods combine the individual experiences and technical knowledge of decision makers (i.e., subjective information) with historical data (i.e., objective information) (Vidal, 2004).

The present study sought to identify the determinants of SMEs' e-commerce practices and structure these factors using fuzzy cognitive mapping. As a PSM, fuzzy cognitive maps (FCMs) can represent the causal reasoning in a decision-making context in a logical, visual way (Hester, 2015). Although FCMs have been applied in a wide range of areas, such as banking (e.g., Azevedo \& Ferreira, 2017; F. Ferreira, J. Ferreira, Fernandes, MeidutèKavaliauskiene், \& Jalali, 2017), real estate (e.g., Ferreira \& Jalali, 2015; Ferreira, 2016; Ribeiro, Ferreira, Jalali, \& Meidutè-Kavaliauskienè, 2017; Fonseca, Ferreira, Fang, \& Jalali, 2018; Pires, Ferreira, Jalali, \& Chang, 2018), and financial investments (e.g., Koulouriotis, 2004), a review of the literature conducted for the current research found no documented use of this methodological approach in any study of SMEs' e-commerce practices. 
The remainder of this paper is organized as follows. The next section presents a review of the literature on e-commerce and SME practices. Section two provides the methodological background. Section three describes the procedures followed to develop a structured understanding of SMEs' e-commerce practices, as well as discussing the results and limitations of the FCM constructed. The last section concludes the paper by presenting the methodological framework's contributions and a roadmap for future research.

\section{Literature review}

E-commerce can be defined as the "process of buying, selling, transferring, or exchanging products, services, and/or information via computer networks, including the Internet" (Turban, Lee, King, McKay, \& Marshall, 2008, p. 4). However, Sin et al. (2016) report that the use of some electronic tools (e.g., electronic mail and websites for promotion purposes only) does not correspond to this concept of e-commerce. The growing number of firms making the transition from a traditional model of commerce to e-commerce is the result of the evolution of technology in business contexts (Choshin \& Ghaffari, 2017).

Nisar and Prabhakar (2017) highlight four main differences between traditional business practices and e-commerce. The first is location since, in traditional commerce, customers choose the nearest store while, in e-commerce, every store is available at a global level and at all hours. The second difference is the absence of physical stores, which allows e-commerce businesses to react quickly to external changes. The third is the impossibility of testing products before transactions take place. The last difference is that e-commerce processes have different characteristics in pre-sale, sale, and post-sale moments. Thus, e-commerce offers "more flexibility, enhanced market outreach, lower cost structures, faster transactions, broader product lines, greater convenience, and customization" (Nisar \& Prabhakar, 2017, p. 137).

E-commerce allows companies to acquire sources of new competitive advantages by reducing costs, improving product quality, reaching more clients and suppliers, and innovating in the ways they sell their products or services (Ngai \& Wat, 2002; Sutanonpaiboon \& Pearson, 2006). As a result, e-commerce can provide SMEs with new opportunities, even for those firms that have resource limitations (Cegarra-Navarro et al., 2007).

According to Savrul et al. (2014), SMEs tend to be operationalized by their owners, reserving for them the responsibility of making decisions at different organizational levels. This centralization allows internal processes to run more rapidly and, depending on the owners' approach, eliminates highly complex organizational structures. Seyal and Rahman (2003) discern six additional SME characteristics. These are: (1) small management teams; (2) a lack of specialized employees; (3) multifunctional management; (4) a lack of control of the business environment; (5) low employee turnover; and (6) an aversion to sophisticated applications. Risk aversion, resource scarcity, and a low market share also prevent SMEs from competing with multinational firms (Rayahu \& Day, 2015).

If SMEs were to apply e-commerce business models, they could make these companies more competitive. E-commerce would reduce their operational and transaction costs; reduce promotion costs; improve communication and coordination with clients, suppliers, and partners; and minimize transportation obstacles. In addition, these models could reduce delivery 
costs and help SMEs reach new markets, thereby overcoming physical and time restraints (Organization for Economic Cooperation and Development [OECD], 2013; Savrul et al., 2014).

Despite the benefits of applying e-commerce business models, MacGregor and Vrazalic (2006) and OECD (2013) have identified multiple barriers that contribute to SMEs' reluctance to engage in e-commerce. Creating a technologically advanced platform is an expensive procedure and requires new competencies. Tax regimes in international transactions are also highly complex, and different countries have different legislation. In addition, low levels of consumer protection can foster fraudulent business practices and damage the reputations of e-commerce businesses. Consumers often mistrust electronic payment procedures (Pinto \& Ferreira, 2010; Ferreira \& Monteiro-Barata, 2011; Ramos, Ferreira, \& Monteiro-Barata, 2011; Reis, Ferreira, \& Monteiro-Barata, 2013). Furthermore, SMEs want short-term returns on investments and prefer traditional transactions. Another barrier is the inapplicability of e-commerce to products. Finally, SMEs must depend on external consultants to acquire the competencies required in e-commerce.

The literature on e-commerce practices discusses some theoretical models that have been used to identify the determinants that explain firms' adoption of e-commerce practices. Some models have a behavioral psychology background, such as the theory of reasoned action (TRA) (Rahayu \& Day, 2015), and theory of perceived behavior (Ajzen, 1991). In the context of research on e-commerce adoption, some authors (e.g., Grandón, Nasco, \& Mykytyn, 2011) have used these frameworks to identify the determinants that influence the prevalence of ecommerce practices. These factors include the following: (1) intentions; (2) attitudes toward behaviors; (3) subjective norms; and (4) perceived behavior controls (Ajzen, 1991). Davis (1989) further created the technology acceptance model (TAM), which applies TRA to technology adoption, identifying attitudes toward behavior, perceived usefulness, and perceived ease of use as determinants.

In addition, innovation diffusion theory (IDT) focuses on the characteristics of innovations perceived by the general population in order to determine the degree of proliferation of a specific technology (Walker, Saffu, \& Mazurek, 2016). However, Sila (2013) criticizes IDT for only concentrating on the technological aspects of technology adoption, so some authors (e.g., Lip-Sam \& Hock-Eam, 2011; Sila, 2013; Rahayu \& Day, 2015; Choshin \& Ghaffari, 2017) have applied a more extensive framework - the technology-organization-environment framework (TOE). This model identifies three categories of variables that explain the adoption of specific technologies. These are: (1) technological factors based on IDT; (2) organizational factors related to firms' capability to adopt technologies; and (3) environmental factors involving external pressures that influence adoption decisions.

Other frameworks have also been used to identify the determinants of companies' ecommerce practices. For example, the unified theory of acceptance and use of technology compiles the contributions of previous models (Venkatesh, Morris, Davis, \& Davis, 2003), while the resource-based view was developed by Barney (1991). Table 1 summarizes some studies that have identified determinants of e-commerce practices.

As Table 1 shows, research focused on identifying determinants that influence SMEs' e-commerce practices includes two steps. First, the researchers ascertain the relevant determinants using the previously mentioned frameworks. Second, the determinants are tested 
Table 1. Studies related to e-commerce determinants

\begin{tabular}{|l|l|l|l|}
\hline \multicolumn{1}{|c|}{ Authors } & \multicolumn{1}{|c|}{ Methods } & \multicolumn{1}{c|}{ Contributions } & \multicolumn{1}{c|}{ Limitations } \\
\hline $\begin{array}{l}\text { Lip-Sam and } \\
\text { Hock-Eam } \\
(2011)\end{array}$ & $\begin{array}{l}\text { TOE and } \\
\text { multinomial logit } \\
\text { model }\end{array}$ & $\begin{array}{l}\text { Incorporates the } \\
\text { characteristics of } \\
\text { SME owners }\end{array}$ & $\begin{array}{l}\text { Only applicable to production } \\
\text { sectors and the study's objective is } \\
\text { to maximize intentions to adopt } \\
\text { e-commerce }\end{array}$ \\
\hline Sila (2013) & $\begin{array}{l}\text { TOE and analysis of } \\
\text { variance test }\end{array}$ & $\begin{array}{l}\text { Incorporates inter- } \\
\text { organizational } \\
\text { factors }\end{array}$ & $\begin{array}{l}\text { Considers a small number of variables } \\
\text { and disregards interactions between } \\
\text { variables }\end{array}$ \\
\hline $\begin{array}{l}\text { Walker et al. } \\
\text { (2016) }\end{array}$ & $\begin{array}{l}\text { TAM, IDT, TOE and } \\
\text { logistic regression }\end{array}$ & $\begin{array}{l}\text { Incorporates firm } \\
\text { positioning }\end{array}$ & $\begin{array}{l}\text { Not applied to developed countries } \\
\text { and omits important factors } \\
\text { (e.g., owner characteristics) }\end{array}$ \\
\hline $\begin{array}{l}\text { Vajjhala and } \\
\text { Thandekkattu } \\
\text { (2017) }\end{array}$ & $\begin{array}{l}\text { Qualitative methods } \\
\text { (i.e., interviews) }\end{array}$ & $\begin{array}{l}\text { Considers subjective } \\
\text { information }\end{array}$ & $\begin{array}{l}\text { Not applied to countries with } \\
\text { different socioeconomic contexts and } \\
\text { omits important factors (e.g., owner } \\
\text { characteristics) }\end{array}$ \\
\hline
\end{tabular}

using an empirical method, usually a statistical tool. The investigation done so far thus has some general limitations. Namely, the methodologies used are not applicable in different contexts, the number of factors identified is low, and the statistical methods used are incapable of representing the cause-and-effect relationships between variables. Therefore, the present study sought to develop a comprehensive cognitive structure representing determinants of SMEs' e-commerce practices and identify the primary factors impacting the adoption of these practices. To this end, we used fuzzy cognitive mapping to ascertain these determinants and analyze their cause-and-effect relationships.

\section{Methodology}

\subsection{Cognitive mapping}

Ribeiro et al. (2017) argue that considering the cognitive bases of decision-making processes offers an opportunity to develop a better understanding of decision problems. Decision makers consider more than just rational aspects when defining their decision criteria (Zavadskas \& Turskis, 2011) as these individuals are also influenced by emotions, instincts, morals, and cultural codes. These introduce a subjective dimension that cannot be omitted from analyses of decision-making processes (Ferreira, 2013). Therefore, in complex decision situations, studies of decision-making processes need to include the diverse interests, expectations, and perspectives that underlie the research context in question, thereby incorporating subjective factors (Cunha \& Morais, 2017).

First introduced by Tolman (1948), cognitive mapping is "the representation of thinking about a problem that follows from the process of mapping. The maps are a network of nodes and arrows as links [...] where the direction of the arrow implies believed causality" (Eden, 2004, p. 673). Thus, cognitive maps can incorporate a large volume of information, identifying aspects (i.e., subjective factors) that are often omitted from other decision-making frameworks (Eden, 2004). 


\subsection{Cognitive maps and FCMs}

Although cognitive maps seek to represent reality through cause-and-effect relationships, Carvalho (2013) and Wisen et al. (2013) argue that these maps are incapable of embodying the real dynamics of problems because cognitive maps cannot quantify the intensity of relationships. Kosko (1986), therefore, developed the FCM approach, which incorporates elements from fuzzy logic and artificial neural networks into cognitive mapping (Stylios \& Groumpos, 1998; Misthos, Messaris, Damigos, \& Menegaki, 2017; Ribeiro et al., 2017).

Kim and Lee (1998, p. 304) define FCMs as "fuzzy signed directed graph[s] with feedback [...that] model the world as a collection of concepts (or factors) and causal relations between concepts". Similarly to cognitive maps, FCMs represent concepts - or events, objectives, and actions - by nodes and the cause-and-effect relationships between them by arrows (Stylios \& Groumpos, 1998; Hester, 2015; Misthos et al., 2017). Alongside the arrows in FCMs, real numbers $w_{i j}$ represent the degree of influence that a tail concept $i$ has on a head concept $j$ (Glykas, 2013). Figure 1 provides an example of an FCM.

The value $w_{i j}$ assumes a real number between -1 and 1 according to three conditions. First, if $w_{i j}<0$, an increase (decrease) in $C_{i}$ leads to a decrease (increase) in $C_{j}$. Second, if $w_{i j}=0$, no relationship exists between $C_{i}$ and $C_{j}$; and, last, if $w_{i j}>0$, an increase (decrease) in $C_{i}$ leads to an increase (decrease) in $C_{j}$ (Hester, 2015; Ferreira, 2016).

In addition to this graphical representation, FCMs can be formulated as a mathematical expression using a state vector $A$ and an adjacent matrix $W$ (Stylios \& Groumpos, 1998; Ferreira, 2016). The state vector $[1 \times n]$, in which $n$ is the number of concepts in the FCM, incorporates the state values $a_{i}$ of every concept within an interval of $[-1 ; 1]$ (Tsadiras, 2008; Salmeron, 2012). The adjacent matrix $W[n \times n]$ comprises the intensity degrees $w_{i j}$ of cause-and-effect relationships between concepts (Ferreira, 2016). Generally, the matrix diagonal is composed only of zeros because a concept rarely causes itself (Stylios \& Groumpos, 1998; Tsadiras, 2008; Ferreira, 2016). However, some authors (e.g. Kok, 2009; Salmeron, 2012;

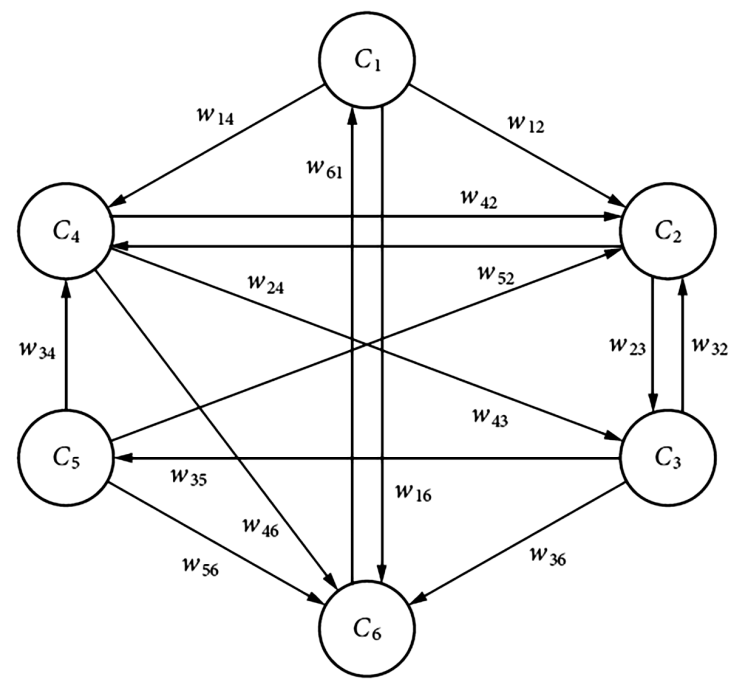

Figure 1. Example of an FCM (source: Kang, Deng, Sadiq, and Mahadevan, 2012, p. 78) 
Carvalho, 2013) consider the existence of non-zero values in the matrix diagonal possible, assuming that some concepts include self-causality.

Despite the complexity of a visual, comprehensive analysis manifested in the mathematical formulation of an FCM, this approach facilitates a better understanding of system behavior even when this is subject to variations (Carvalho, 2013). According to Stylios and Groumpos (1998), a state value can be predicted by Equation (1):

$$
A_{i}^{(t+1)}=f\left(A_{i}^{(t)}+\sum_{\substack{j=1 \\ j \neq i}}^{n} A_{j}^{(t)} \cdot w_{j i}\right),
$$

in which $A_{i}{ }^{(t+1)}$ is the activation level of concept $i$ at moment $t+1$. In addition, $A_{j}{ }^{(t)}$ is the activation level of concept $j$ at moment $t, w_{j i}$ is the degree of intensity of the relationship that connects concept $j$ to concept $i$, and $f$ is the threshold function that confines the state value to an interval. The threshold function can assume different forms: (1) binary (i.e., $f(x)=0$ or 1 ); (2) trivalent (i.e., $f(x)=-1,0$ or 1); (3) sigmoid (i.e., $f(x) \in[0 ; 1]$ ); or (4) hyperbolic tangent (i.e., $f(x) \in[-1 ; 1])$ (Azevedo \& Ferreira, 2017). This function enables qualitative comparisons between concepts and assigns them a meaning (Mazlack, 2009).

Tsadiras (2008) further allocates the different threshold functions in two ways according to the decision-making context. Binary and sigmoid functions are used for problems in which the concepts' states are activated or deactivated. Trivalent and hyperbolic tangent functions are used in contexts in which concepts can increase, decrease, or stabilize.

Due to their mathematical basis, FCMs can be used to analyze systems' temporal evolution based on the impacts of cause-and-effect relationships, thereby producing a transparent, well-informed, and logical decision-making framework (Tsadiras, 2008). In this dynamic analysis, the system in question is submitted to an initial stimulus (i.e., attribution of an activation level to one or more concepts) that could represent its current state or a possible scenario (Stylios \& Groumpos, 1998; Tsadiras, 2008; Misthos et al., 2017). Next, according to Koulouriotis (2004, p. 217), the intensity degrees of the cause-and-effect relationships cause an "iterative mechanism [to occur], which propagates in the network the initial node stimulations and, [...in] this way, estimates the direct and indirect effects ending in each concept".

After some iterations, this causal propagation results in three possible system behaviors: (1) an equilibrium point; (2) cyclic behavior; or (3) chaotic behavior (Salmeron, 2012). With this feature of FCMs, decision makers can formulate "what-if" questions, thus facilitating a better understanding of the decision problem and more consistent decisions (Yaman \& Polat, 2009; F. Ferreira, Jalali, \& J. Ferreira, 2016; Carlucci, Ferreira, Schiuma, Jalali, \& António, 2018).

\section{Application and results}

To develop an FCM for an analysis of determinants of SMEs' e-commerce practices, the first step was to form a panel of experts in this field. Fuzzy cognitive mapping "is a process that extracts [...] knowledge from [...] participants in order to describe and investigate the problem's model and behavior" (Misthos et al., 2017, p. 62). 


\subsection{Participants}

Stylios and Groumpos (1998) argue that the FCM development process needs to be supported by a panel of decision makers (i.e., experts) for two reasons. These are that these individuals know the factors that influence the relevant system's behavior and that these decision makers are familiar with the cause-and-effect relationships between those factors. Yaman and Polat (2009, p. 387) further note that "using a group of experts has the benefit of improving the reliability of the final model".

In this study, a panel of six decision makers was created based on the following guidelines. First, the facilitators needed to "relate personally to a small number (say, three to ten persons)" (Eden \& Ackermann, 2001, p. 22). Second, the participants had to include managers with knowledge and experience in SMEs' e-commerce practices. Third, the panel needed to incorporate decision makers with elevated levels of responsibility in SMEs. Fourth, the participants had to come from multiple business areas. Last, the experts needed to be heterogeneous in terms of gender, age, and professional experience.

Thus, the panel comprised founders, owners, and managers from different SMEs from the ticketing, food, alcoholic beverages, refrigeration, equipment maintenance, and home appliance sectors. The experts were available to participate in two four-hour group workshops (i.e., a total of eight hours). The process-oriented nature of the methodological framework applied is significant as this suggests the procedures followed may work well with other groups of decision makers. According to Bell and Morse (2013, p. 962), this means "there is less emphasis on outputs per se and more focus on process".

\subsection{Cognitive structure construction}

The objective of the first group session was to identify the determinants of SMEs' e-commerce practices and structure these factors into a cognitive map that could be converted into an FCM. Before starting this session, the methodologies to be applied were briefly introduced to avoid misunderstandings between the panel members and facilitators (i.e., two of this paper's authors). The following trigger question was then asked: "Based on your personal values and professional experience, what factors influence SMEs' practice of e-commerce?". This question sought to stimulate reflection on the problem and start a discussion among the panel members (Tegarden \& Sheetz, 2003).

The first phase of this session thus focused on identifying the determinants/criteria using the "post-its technique" (Eden \& Ackermann, 2001). In this procedure, "panel members [are] invited to share opinions, perceptions, experiences and values and, in sequence, to identify relevant criteria for the problem at hand, writing these criteria on post-its (i.e., one criterion per post-it)" (Ribeiro et al., 2017, p. 147). In the second phase, the decision makers organized the determinants obtained into clusters, resulting in the following six groups: entrepreneur profile; market; operational management; marketing and promotions; website and digital platform; and products.

Inside each cluster, the determinants were reorganized according to their relative importance so that the most important determinants were placed at the top of the cluster and the least important at the bottom. After a final validation by the panel members, the cognitive structure was input into a computer using the Decision Explorer software (www.banxia.com). Figure 2 presents the collective cognitive structure developed. 


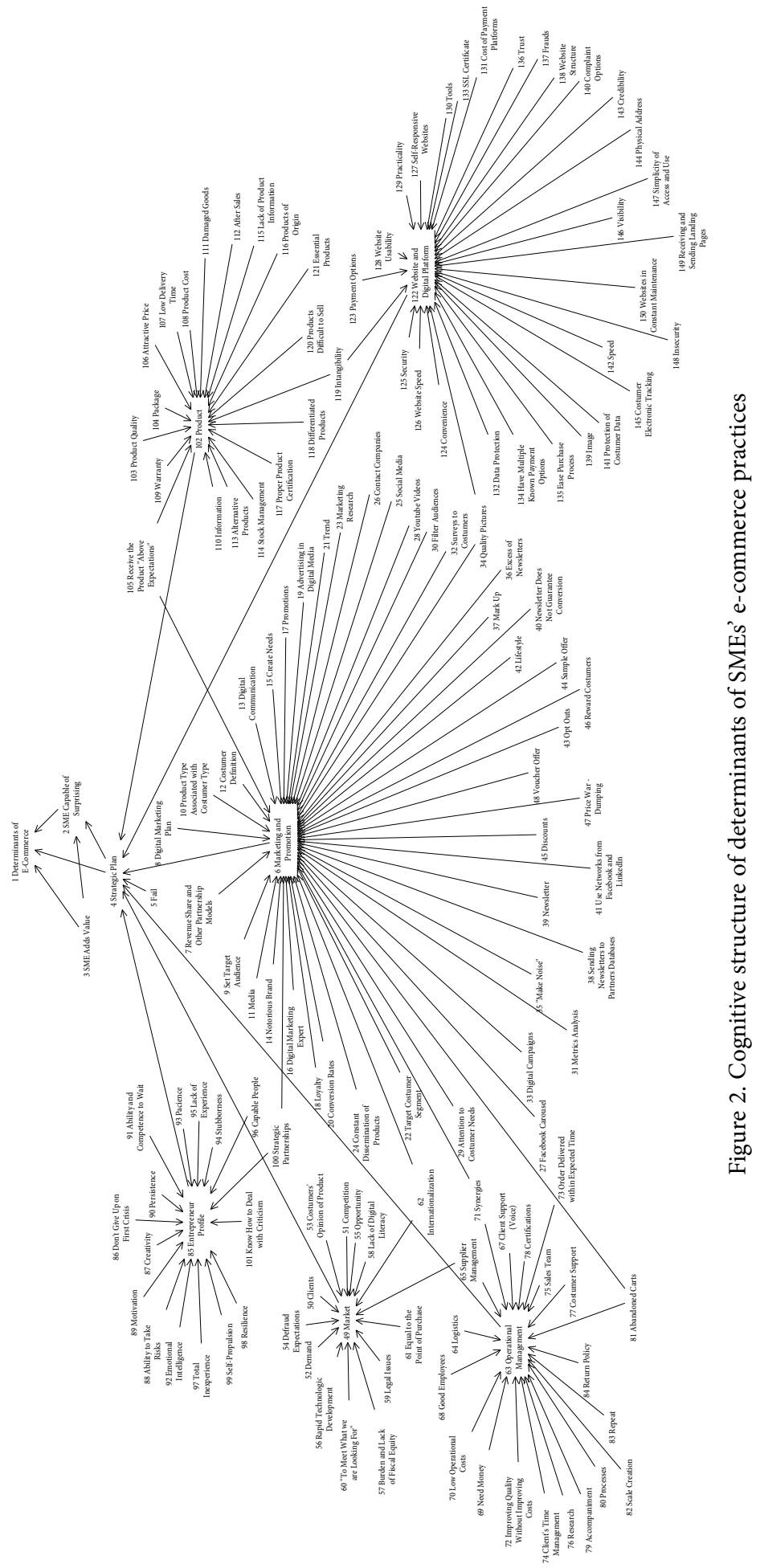


This structure used arrows to represent cause-and-effect relationships between concepts, thus expediting the visualization of the system and improving the decision makers' understanding of SMEs' e-commerce practices. Notably, the constructivist approach of the methodologies applied facilitated continuous learning through discussions and negotiations among the panel members. This improved the relevance of the procedures followed and reinforced the process-oriented nature of the methodological framework (U. Özesmi \& S. Özesmi, 2004; F. Ferreira, Jalali, J. Ferreira, Stankevičienè, \& Marques, 2016).

\subsection{FCM development}

Because "simple" cognitive maps are unable to represent the dynamic nature of reality (Carvalho, 2013), the next phase involved developing an FCM. As noted in section 2.2, the system's dynamics were represented by fuzzy quantification of the cause-and-effect relationships using an interval from -1 to 1 (Ferreira, 2016).

In the second group session, the decision makers were asked to quantify the cause-andeffect relationships identified in the previous meeting. The panel was also informed that they needed to determine intervals according to the type of relationship in question. This meant that, for positive relationships (i.e., an increase [decrease] in a tail concept would increase [decrease] a head concept), the panel had to use the ]0; 1] interval. For negative relationships (i.e., an increase [decrease] in a tail concept would decrease [increase] a head concept), the decision makers should use the [-1;0 [ interval. Zero was excluded because it would mean that no relationship exists between the concepts.

In this session, the decision makers constantly engaged in negotiations and discussions since all degrees of intensity were carefully debated and collectively accepted. Given the heterogeneity of experiences and business areas represented in the panel, ideas about the relationships between determinants and their degree of intensity differed between decision makers, making negotiation a key component in this phase. With all the relationships quantified, the FCM could be created and digitalized using the FCMapper (www.fcmappers.net) and Pajek (www.mrvar.fdv.uni-lj.si/pajek) software packages. Figure 3 shows the cognitive structure of what, at a later stage, would become the final FCM. To simplify this figure, all labels have been removed, but the complete version of the cognitive structure developed containing all specifications is available upon request.

After the FCM had been constructed, the intensities of the various connections within it were inserted into the adjacency matrix as required by this methodology's theoretical framework. Size restrictions make including the adjacency matrix in this paper impossible. However, Table 2 provides an example of the matrix used, in which $C_{i}$ and $w_{i j}$ were defined by the panel members as a group.

The values $w_{i j}$ were directly determined by the decision makers following a lengthy negotiation process. Figure 4 offers an example of this exercise by presenting the first cluster (i.e., entrepreneur profile) in which each connection's degree of intensity lies within the range $[-1,1]$.

After various tests and simulations were conducted to ensure the system's stability, the visualization and analysis of the FCM's dynamics provided the decision makers with an overview of the impact each determinant could have on SMEs' e-commerce practices. 


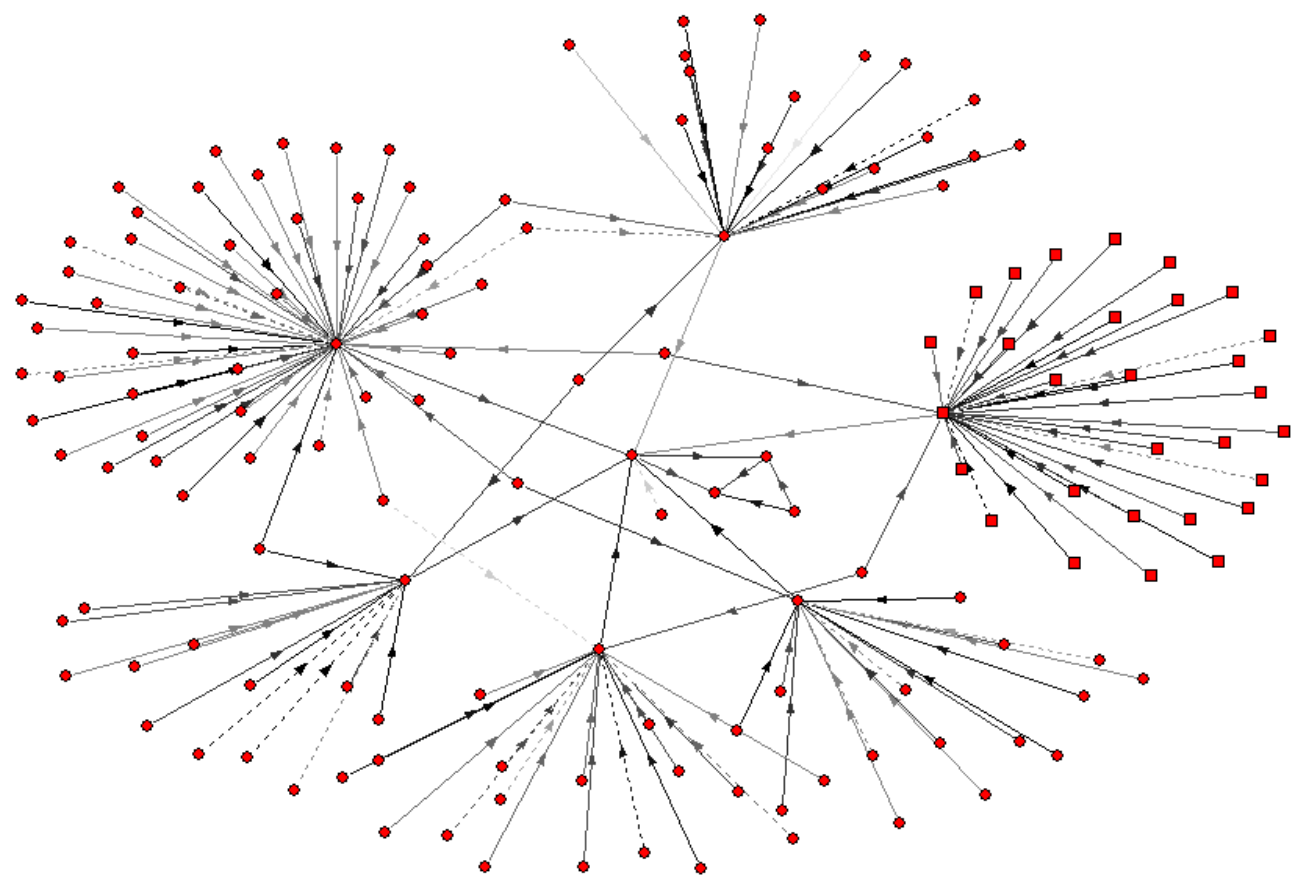

Figure 3. FCM of determinants of SMEs' e-commerce practices

Table 2. Adjacency matrix

\begin{tabular}{|c|c|c|c|c|c|}
\hline & $C_{1}$ & $C_{2}$ & $\ldots$ & $C_{n-1}$ & $C_{n}$ \\
\hline$C_{1}$ & 0 & $w_{12}$ & $\ldots$ & $w_{1 n-1}$ & $w_{1 n}$ \\
\hline$C_{2}$ & $w_{21}$ & 0 & $\ldots$ & $w_{2 n-1}$ & $w_{2 n}$ \\
\hline$\ldots$ & $\ldots$ & $\ldots$ & $\ldots$ & $\ldots$ & $\ldots$ \\
\hline$C_{n-1}$ & $w_{n-11}$ & $w_{n-12}$ & $\ldots$ & 0 & $w_{n-1 n}$ \\
\hline$C_{n}$ & $w_{n 1}$ & $w_{n 2}$ & $\ldots$ & $w_{n n-1}$ & 0 \\
\hline
\end{tabular}

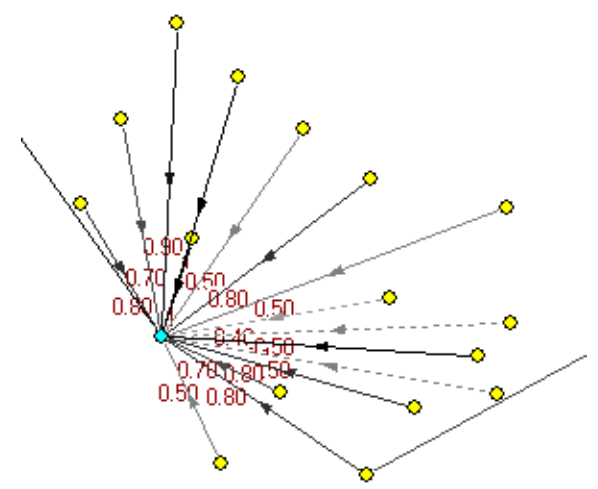

Figure 4. Analysis of degrees of intensity for entrepreneur profile 
As Carlucci, Schiuma, Gavrilova, and Linzalone (2013, p. 216) point out, "once the FCM has been constructed, it can be used to model and simulate the behavior of the system including performance objectives, process performance objectives and knowledge assets". The present study's next stage was based on the panel's analysis of the key determinants influencing SMEs' e-commerce practices.

\subsection{Static and dynamic analyses of results}

According to Tsadiras (2008), analyses of FCMs can be conducted to facilitate both identifying the factors with the most impact on the system and predicting its behavior in plausible scenarios through variations in determinants. Ferreira (2016) classifies these two forms of analysis as static and dynamic, respectively. The first analysis conducted in the current research was static, in which no changes were made in the system's values - either in determinants/concepts or in cause-and-effect relationships.

\subsubsection{Static analysis}

Static analysis is based on the determinants' degree of centrality. This indicator assesses the influence that a determinant has in the system under study, such that a high degree of centrality means that the determinant is extremely important in the system (Ribeiro et al., 2017). The degree of centrality is the sum of a determinant's indegree and outdegree (Misthos et al., 2017). Table 3 lists the determinants of SMEs' e-commerce practices with the highest degree of centrality. The complete list of determinants and their respective degree of centrality is available upon request.

Table 3. Degree of centrality of determinants of SME e-commerce

\begin{tabular}{|l|c|c|c|}
\hline \multicolumn{1}{|c|}{ Determinant/Criterion } & Outdegree & Indegree & Centrality \\
\hline Marketing and promotions & 0.70 & 29.90 & 30.60 \\
\hline Website and digital platform & 0.50 & 23.60 & 24.10 \\
\hline Operational management & 0.40 & 14.50 & 14.90 \\
\hline Products & 0.90 & 12.80 & 13.70 \\
\hline Entrepreneur profile & 1.00 & 11.40 & 12.40 \\
\hline Market & 0.80 & 10.70 & 11.50 \\
\hline
\end{tabular}

The decision makers decided that the most significant determinant of SMEs' e-commerce practices is marketing and promotions (30.60), followed by website and digital platform (24.10), operational management (14.90), products (13.70), entrepreneur profile (12.40), and market (11.50). These results were compared with the existing literature related to e-commerce practices, revealing that the conclusions drawn in the present study corroborate the findings of the previous theoretical frameworks used to identify e-commerce determinants.

Thus, the factors found in the present study are consistent with the TOE framework used by different authors (e.g., Zhang \& Dhaliwal, 2009; Lip-Sam \& Hock-Eam, 2011; Sila, 
2013). More specifically, technological factors are related to the website and digital platform determinant. Organizational factors are represented by operational management and marketing and promotions. Finally, environmental factors are covered by market. Some researchers have considered the TOE framework to be too limited and added owner and/or manager characteristics to their models ( $c f$. Rahayu \& Day, 2015), while the present model includes entrepreneur profile as a determinant of SMEs' e-commerce practices.

Beyond its compliance with the literature, the cognitive structure developed in this study identifies a more diverse group of factors and appraises their influence on SMEs' e-commerce practices in a transparent and logical way. By identifying the most significant factors influencing SME e-commerce, these results can help decision makers measure SMEs' performance through control systems (Hester, 2015; Olazabal, Chiabai, Foudi, \& Neumann, 2018).

\subsubsection{Dynamic analysis}

Dynamic analysis implies the assignment of activation values to concepts (see section 2.2) that represent a scenario so that the system's behavior evolves and the effects of that scenario can be predicted (Misthos et al., 2017). The present study performed this analysis using the Mental Modeler software (www.mentalmodeler.org), dividing the analysis into three levels: (1) clusters; (2) intra-cluster factors; and (3) multi-cluster determinants.

\subsubsection{Dynamic analysis of clusters}

As can be seen in the cognitive structure developed (see Figure 2), the panel of decision makers concluded that the determinant labeled "Strategic Plan" is one of the most significant factors in SMEs' e-commerce practices, as it connects all six clusters. According to the participants' perceptions, the determinants represented by these clusters are important components of strategic plans regarding SME e-commerce. Therefore, this analysis submitted each cluster to multiple variations (i.e., $-0.50 ; 0.75$; and 1.00) to understand better their impact on strategic plans. Figures 5, 6, and 7 present the variation of this determinant when each cluster changed by $-0.50,0.75$, and 1.00 , respectively.

Beyond the above variations of clusters, the determinant labeled "Fail" was also submitted to variations because it has a direct cause-and-effect relationship with strategic planning. As shown in Figures 5, 6, and 7, failures have a negative impact on strategic plans compared with the clusters overall. This happens because failures have a negative cause-and-effect relationship with strategic plans, while clusters have a positive cause-and-effect relationship with the latter determinant. Thus, when failure rates decrease or increase, this induces an increase or decrease in strategic planning.

In broader terms, the clusters' influence on strategic plans is almost the same for the different variations simulated. Entrepreneur profile is the cluster with the strongest influence (0.76 in a 1.00 variation), followed by products (0.72), market (0.66), marketing and promotions ( 0.60$)$, website and digital platform ( 0.46$)$, and operational management ( 0.38$)$. In decision-making processes, the conclusions based on this analysis can help decision makers rationalize their choices about allocating resources to the component of strategic plans rather than other factors. 


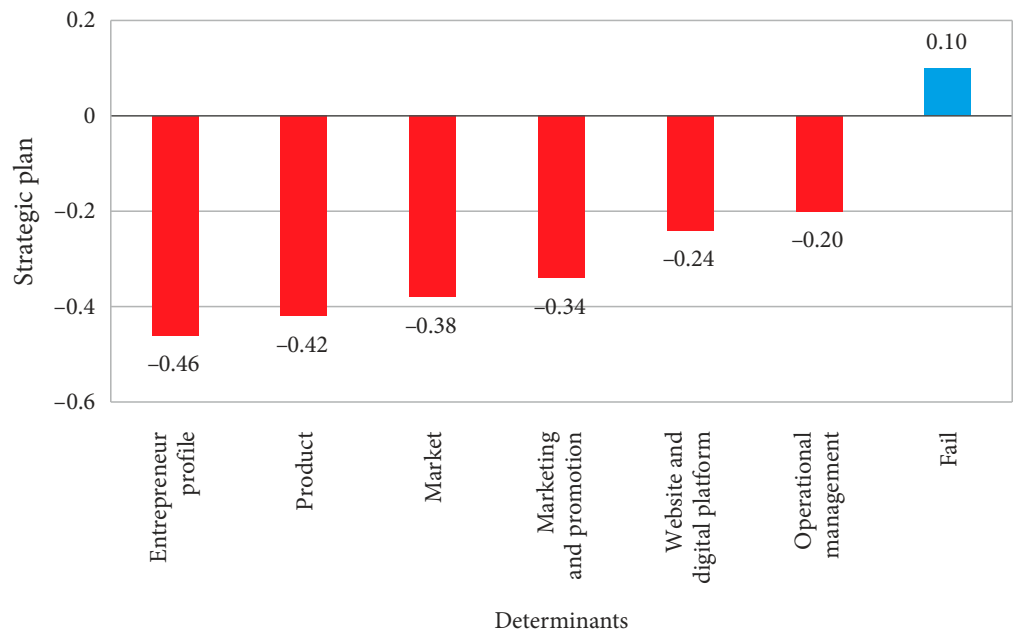

Figure 5. Impact on strategic plan of -0.50 variation in each cluster

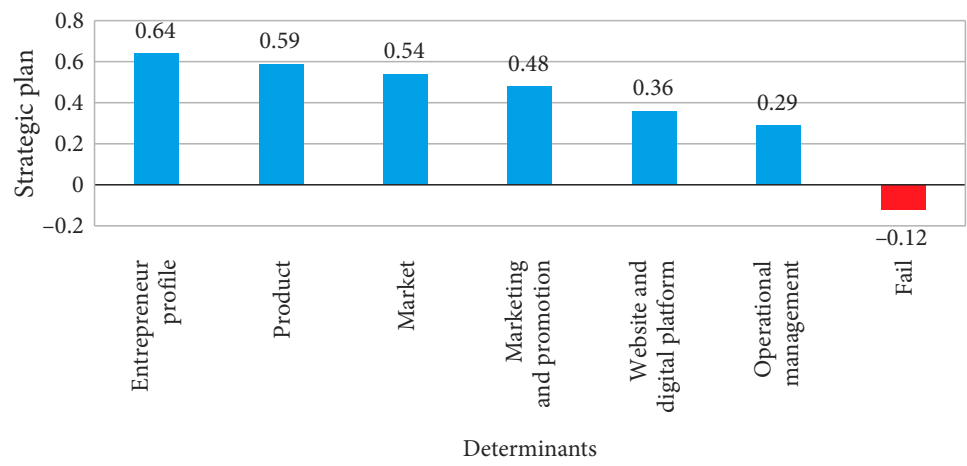

Figure 6. Impact on strategic plan of 0.75 variation in each cluster

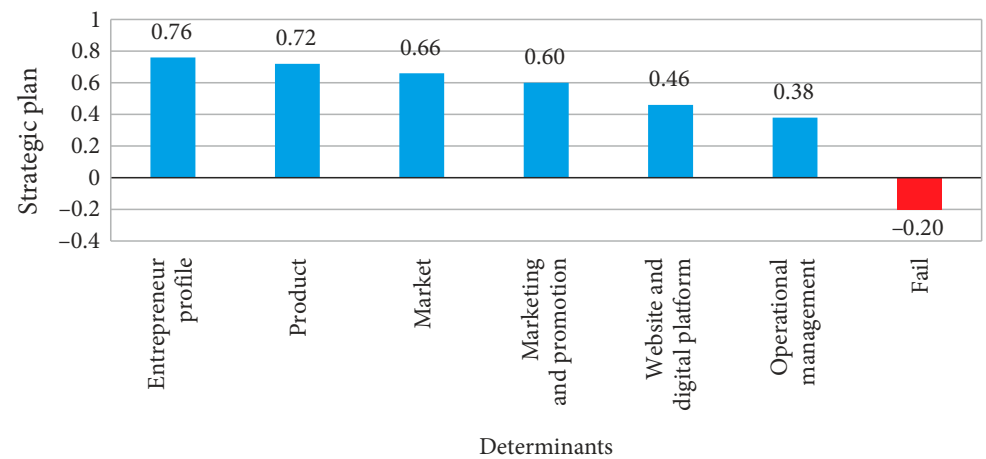

Figure 7. Impact on strategic plan of 1.00 variation in each cluster 


\subsubsection{Dynamic analysis at intra-cluster level}

In the analysis conducted at the intra-cluster level, some determinants of each cluster were selected by the panel members and submitted to variations of $-0.50,0.75$, and 1.00 , to appraise their effects on each cluster. Tables 4 through 9 present the impacts of some of these determinants on entrepreneur profile, market, operational management, marketing and promotions, website and digital platform, and products, respectively.

Table 4. Analysis of entrepreneur profile

\begin{tabular}{|l|c|c|c|c|}
\hline \multicolumn{1}{|c|}{ Determinant } & $\begin{array}{c}\text { Intensity } \\
\text { degree }\end{array}$ & $\begin{array}{c}-0.50 \\
\text { Variation }\end{array}$ & $\begin{array}{c}0.75 \\
\text { Variation }\end{array}$ & $\begin{array}{c}1.00 \\
\text { Variation }\end{array}$ \\
\hline Creativity & 0.70 & -0.34 & 0.48 & 0.60 \\
\hline Ability to take risks & 1.00 & -0.46 & 0.64 & 0.76 \\
\hline Total inexperience & -0.50 & 0.24 & -0.36 & -0.46 \\
\hline Understanding how to deal with criticism & 0.50 & -0.24 & 0.36 & 0.46 \\
\hline
\end{tabular}

Table 5. Analysis of market

\begin{tabular}{|l|c|c|c|c|}
\hline \multicolumn{1}{|c|}{ Determinant } & $\begin{array}{c}\text { Intensity } \\
\text { degree }\end{array}$ & $\begin{array}{c}-0.50 \\
\text { Variation }\end{array}$ & $\begin{array}{c}0.75 \\
\text { Variation }\end{array}$ & $\begin{array}{c}1.00 \\
\text { Variation }\end{array}$ \\
\hline Demand & 0.80 & -0.38 & 0.54 & 0.66 \\
\hline Burden and lack of fiscal equity & -0.50 & 0.24 & -0.36 & -0.46 \\
\hline Lack of digital literacy & -1.0 & 0.46 & -0.64 & -0.76 \\
\hline Competition & 0.70 & -0.34 & 0.48 & 0.60 \\
\hline
\end{tabular}

Table 6. Analysis of operational management

\begin{tabular}{|l|c|c|c|c|}
\hline \multicolumn{1}{|c|}{ Determinant } & $\begin{array}{c}\text { Intensity } \\
\text { degree }\end{array}$ & $\begin{array}{c}-0.50 \\
\text { Variation }\end{array}$ & $\begin{array}{c}0.75 \\
\text { Variation }\end{array}$ & $\begin{array}{c}1.00 \\
\text { Variation }\end{array}$ \\
\hline Money needs & -1.0 & 0.46 & -0.64 & -0.76 \\
\hline Clients' time management & 0.60 & -0.29 & 0.42 & 0.54 \\
\hline Accompaniment & 0.30 & -0.15 & 0.22 & 0.29 \\
\hline Sales team & 0.10 & -0.05 & 0.07 & 0.10 \\
\hline
\end{tabular}

Table 7. Analysis of marketing and promotions

\begin{tabular}{|l|c|c|c|c|}
\hline \multicolumn{1}{|c|}{ Determinant } & $\begin{array}{c}\text { Intensity } \\
\text { degree }\end{array}$ & $\begin{array}{c}-0.50 \\
\text { Variation }\end{array}$ & $\begin{array}{c}0.75 \\
\text { Variation }\end{array}$ & $\begin{array}{c}1.00 \\
\text { Variation }\end{array}$ \\
\hline Famous brand & 0.70 & -0.34 & 0.48 & 0.60 \\
\hline Loyalty & 1.0 & -0.46 & 0.64 & 0.76 \\
\hline Opt-outs & -0.50 & 0.24 & -0.36 & -0.46 \\
\hline Costumer surveys & 0.50 & -0.24 & 0.36 & 0.46 \\
\hline
\end{tabular}


Table 8. Analysis of website and digital platform

\begin{tabular}{|l|c|c|c|c|}
\hline \multicolumn{1}{|c|}{ Determinant } & $\begin{array}{c}\text { Intensity } \\
\text { degree }\end{array}$ & $\begin{array}{c}-0.50 \\
\text { Variation }\end{array}$ & $\begin{array}{c}0.75 \\
\text { Variation }\end{array}$ & $\begin{array}{c}1.00 \\
\text { Variation }\end{array}$ \\
\hline Web usability & 1.00 & -0.46 & 0.64 & 0.76 \\
\hline Trust & 0.80 & -0.38 & 0.54 & 0.66 \\
\hline Website structure & 0.70 & -0.34 & 0.48 & 0.60 \\
\hline Constant maintenance of website & -0.50 & 0.24 & -0.36 & -0.46 \\
\hline
\end{tabular}

Table 9. Analysis of products

\begin{tabular}{|l|c|c|c|c|}
\hline \multicolumn{1}{|c|}{ Determinant } & $\begin{array}{c}\text { Intensity } \\
\text { degree }\end{array}$ & $\begin{array}{c}-0.50 \\
\text { Variation }\end{array}$ & $\begin{array}{c}0.75 \\
\text { Variation }\end{array}$ & $\begin{array}{c}1.00 \\
\text { Variation }\end{array}$ \\
\hline Product cost & -0.90 & 0.42 & -0.59 & -0.72 \\
\hline Lack of product information & -0.40 & 0.20 & -0.29 & -0.38 \\
\hline Products of origin & 0.50 & -0.24 & 0.36 & 0.46 \\
\hline Alternative products & 0.60 & -0.29 & 0.42 & 0.54 \\
\hline
\end{tabular}

As can be seen at this level of analysis, the impact of a determinant is related to its degree of intensity so that the greater the weight of the cause-and-effect relationship, the greater the variation of the head concept. This analysis at the intra-cluster level provides support for decision-making processes because the results include identifying the causes of a cluster's behavior. Similar to the cluster level analysis, an intra-cluster evaluation facilitates the identification of alternatives when allocating resources.

\subsubsection{Dynamic analysis of multi-cluster determinants}

A third type of analysis was carried out to examine the impact on the system of determinants with cause-and-effect relationships involving multiple clusters. This level of analysis is important because these determinants generate multiple effects and, consequently, influence strategic plans and the other determinants of this causal chain.

In other words, with a single variation in one of these determinants, the system will show greater variation than if that determinant only has one causal link. This level of analysis submitted each multi-cluster determinant to a 0.50 variation, and the most significant concept of the system (i.e., determinants of SME e-commerce) was studied. Figure 8 presents the results obtained.

As can be seen in Figure 8, when some determinants vary 0.50 (i.e., internationalization, strategic partnerships, intangibility, and supplier management), the system's most important determinant has a higher variation (i.e., 0.62; 0.61; 0.52; and 0.51, respectively). This means that these determinants strongly influence SMEs' e-commerce practices. The determinants with less impact are synergies (0.45), quality pictures (0.41), abandoned carts $(-0.30)$, and products that exceed expectations (0.11). Figure 9 presents the effects of a 0.50 variation on this logical chain.

The decision makers' collective perception was that strategic partnerships are related to managers' ability to surround themselves with partners who can help these managers leverage 
their business, thereby affecting the entrepreneur profile determinant. These partnerships are also useful in brand promotion, which is a marketing and promotions component. Another example of the analysis carried out at the multi-cluster level was the products that exceed expectations determinant. Figure 10 presents the effects of a 0.50 variation on this logical chain.

The panel decided that, as a determinant of marketing and promotions, products that exceed expectations have a positive impact $(0.24)$ because they improve customer satisfaction. However, as a component of products, exceeding expectations has a negative impact on subsequent purchases because customers will not accept products or services that "only" meet their expectations, with the overall cluster reflecting this tendency $(-0.10)$. Analyses at this level were carried out for different logical chains in the cognitive structure created, which resulted in a deeper reflection on and fuller understanding of the determinants of SMEs' e-commerce practices.

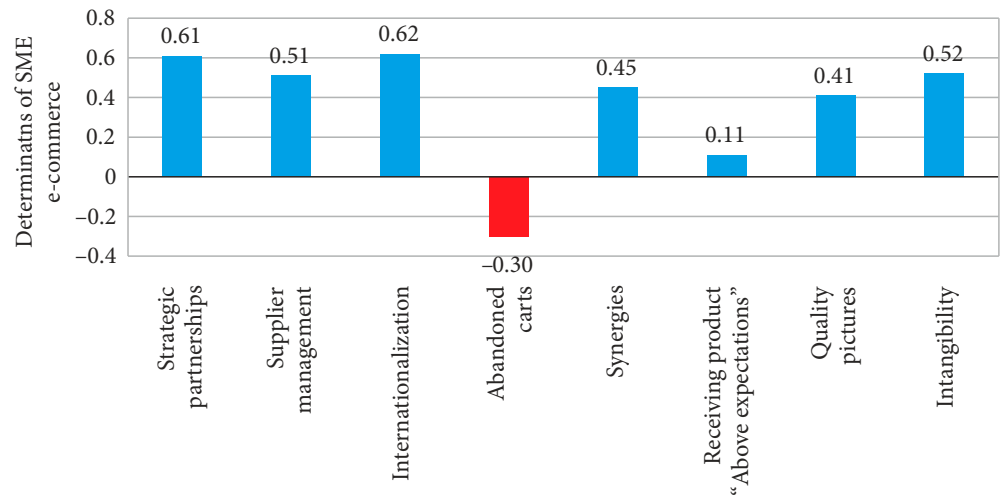

Figure 8. Multi-cluster determinants' impact on determinants of SME e-commerce

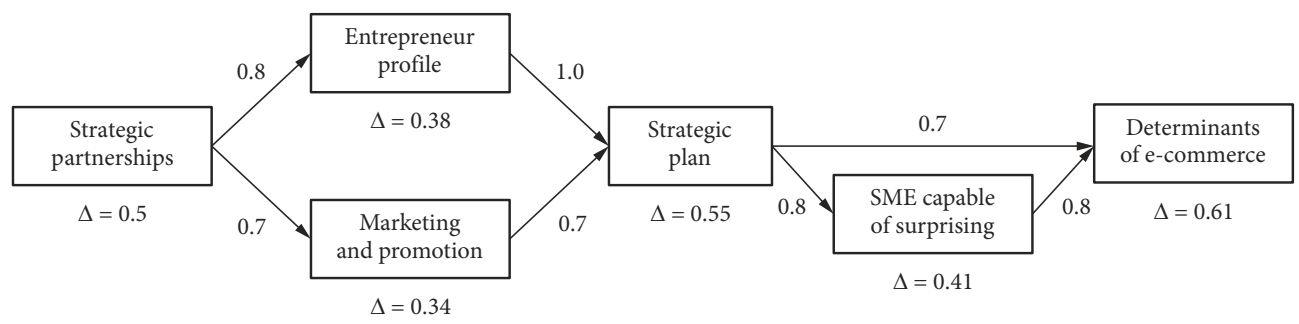

Figure 9. Impact of variation on strategic partnerships

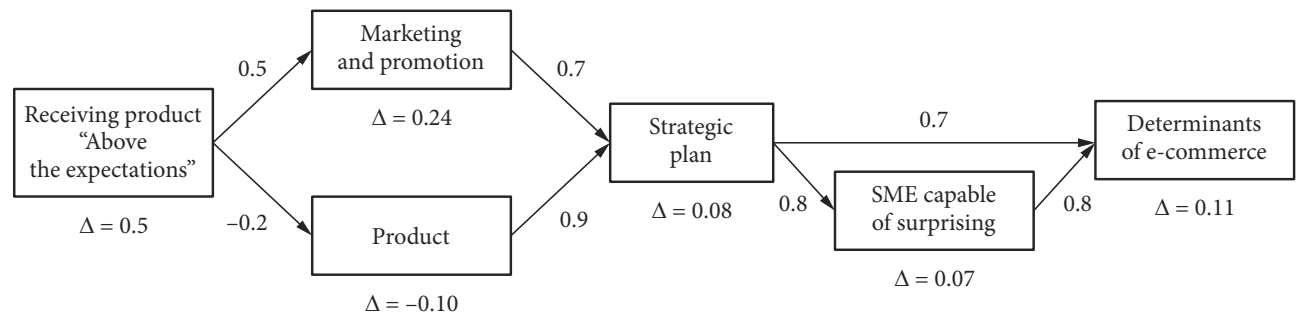

Figure 10. Impact of variation in products that exceed expectations 


\subsection{Validation, limitations, and recommendations}

The representation of e-commerce practices as an FCM required the organization of information extracted from a group of decision makers. The results include a clearer comprehension of SMEs' e-commerce practices, analyses of combinations of multiple factors, and the ability to appraise the behavior of the system generated when different scenarios are simulated.

The panel members agreed that the development of a model that represents SMEs' ecommerce practices is useful for improving these firms' business. Because SMEs' daily objective is "survival", according to one of the decision makers, a structured system in which determinants of e-commerce practices are clearly identified facilitates better resource allocation and comprehension of business behaviors. This, in turn, can accelerate decision-making processes and produce consistent decisions.

Because the cognitive structure developed in this study is idiosyncratic, any alteration in the elements of the group sessions (e.g., decision makers, facilitators, and procedures) could result in a different representation of the system (Gray et al., 2013). Consequently, extrapolations of the present research's findings are not recommended, and their application in different contexts must be done cautiously, including adapting the model whenever necessary. Nonetheless, the constructivist and process-oriented nature of the methodology applied means that the FCM generated is a flexible tool that allows for adjustments and updates with new information and focuses on continuously improving its outputs (Yaman \& Polat, 2009; Ferreira, 2016).

\section{Conclusions}

Since SMEs seldom apply e-commerce business models in their operations, the present study sought to identify and structure the determinants influencing e-commerce practices from SMEs' perspective by using fuzzy cognitive mapping.

When compared to the extant literature, this research corroborates some previous findings, including that four major groups of determinants exist. The first is technological factors, corresponding in this study to the website and digital platform determinant. The second is organizational factors involving operational management and marketing and promotions. The third is environmental factors, represented by the market determinant. The last group is owner and/or manager profile factors, characterized by the entrepreneur profile determinant. In addition, the construction of an FCM facilitated the identification of a greater number of determinants, including product characteristics. The FCM also revealed the links between determinants in terms of causal logic, showing interrelationships more clearly. Finally, this methodology adapted the model to a specific context and incorporated subjective elements related to the decision problem.

According to Olazabal and Pascual (2016, p. 19), "FCM is an interesting tool with numerous comparative advantages including the ability to simplify a complex decision environment while integrating actors' different perspectives and ideas using a semi-quantitative approach". Thus, the present study's framework produced new insights into this topic and formulated a more complete conception of SMEs' e-commerce practices. The result is a well-informed framework validated by the panel members who participated in the group sessions, which fa- 
cilitates analyses of the dynamics behind SMEs' e-commerce practices. No previous evidence of the use of the FCM approach in this context was found, confirming that the proposed methodology makes a significant contribution to the existing literature on e-commerce and SME business development.

By measuring the intensity of the cause-and-effect relationships between determinants, the proposed approach further fosters greater transparency in the way variables interact with each other. This methodology allows for the incorporation of new information and adds to the body of knowledge on SMEs' e-commerce practices. Although the findings are idiosyncratic, as argued previously, they can be an important starting point for other researchers and practitioners seeking to analyze and assess determinants of SME e-commerce. In addition, because the approach applied is process-oriented, the procedures followed can be replicated in other contexts or with different groups of participants (cf. Bell \& Morse, 2013).

Although the proposed model is based on a complementary - as opposed to comparative - methodological perspective, future investigations might consider replicating the FCM processes followed in this study with different participants. In addition, researchers could extend this approach to other contexts and combine it with different methods to make the analyses more robust. This would contribute to a fuller understanding of e-commerce practices in other environments and extend the application of this study's model to wider, transversal contexts. Any further advancement in research on SMEs' e-commerce practices would be welcomed.

\section{Acknowledgements}

Records of the expert panel meetings, including pictures, software output and non-confidential information of the study, can be obtained from the corresponding author upon request. The authors gratefully acknowledge the superb contribution and knowledge sharing of the panel members: Carla Simões, Mário Silva, Nuno Antunes, Rita Amado, Rogério Meireis, and Rui Costa. Facility support from ISCTE Business School, University Institute of Lisbon, Portugal, is also acknowledged.

\section{References}

Ajzen, I. (1991). The theory of planned behaviour. Organizational Behavior and Human Decision Processes, 50(2), 179-211. https://doi.org/10.1016/0749-5978(91)90020-T

Azevedo, A., \& Ferreira, F. (2017). Analyzing the dynamics behind ethical banking practices using fuzzy cognitive mapping. Operational Research: An International Journal. https://doi.org/10.1007/s12351-017-0333-6

Barney, J. (1991). Firm resources and sustained competitive advantage. Journal of Management, 17(1), 99-120. https://doi.org/10.1177/014920639101700108

Bell, S., \& Morse, S. (2013). Groups and facilitators within problem structuring processes. Journal of the Operational Research Society, 64(7), 959-972. https://doi.org/10.1057/jors.2012.110

Belton, V., Ackermann, F., \& Shepherd, I. (1997). Integrated support from problem structuring through to alternative evaluating using COPE and V.I.S.A. Journal of Multi-Criteria Decision Analysis, 6(3), 115-130. https://doi.org/10.1002/(SICI)1099-1360(199705)6:3<115::AID-MCDA140>3.0.CO;2-I 
Carlucci, D., Ferreira, F., Schiuma, G., Jalali, M., \& António, N. (2018). A holistic conception of sustainable banking: adding value with fuzzy cognitive mapping. Technological and Economic Development of Economy, 24(4), 1303-1322. https://doi.org/10.3846/20294913.2016.1266412

Carlucci, D., Schiuma, G., Gavrilova, T., \& Linzalone, R. (2013). A fuzzy cognitive map based approach to disclose value creation dynamics of ABIs. Paper presented at the Proceedings of the 8th international forum on knowledge asset dynamics (IFKAD-2013), 12-14 June 2013, Zagreb, Croatia.

Carvalho, J. (2013). On semantics and the use of fuzzy cognitive maps and dynamic cognitive maps in social sciences. Fuzzy Sets and Systems, 214, 6-19. https://doi.org/10.1016/j.fss.2011.12.009

Castela, B., Ferreira, F., Ferreira, J., \& Marques, C. (2018). Assessing the innovation capability of smalland medium-sized enterprises using a non-parametric and integrative approach. Management Decision, 56(6), 1365-1383. https://doi.org/10.1108/MD-02-2017-0156

Cegarra-Navarro, J., Jiménez, D., \& Martínez-Conesa, E. (2007). Implementing e-business through organizational learning: an empirical investigation in SMEs. International Journal of Investigation Management, 27(3), 173-186. https://doi.org/10.1016/j.ijinfomgt.2007.01.001

Child, J., Hsieh, L., Elbanna, S., Karmowska, J., Marinova, S., Puthusserry, P., Tsai, T., Narooz, R., \& Zhang, Y. (2017). SME international business models: the role of context and experience. Journal of World Business, 52(5), 664-679. https://doi.org/10.1016/j.jwb.2017.05.004

Choshin, M., \& Ghaffari, A. (2017). An investigation of the impact of effective factors on the success of e-commerce in small- and medium-sized companies. Computers in Human Behavior, 66, 67-74. https://doi.org/10.1016/j.chb.2016.09.026

Cunha, A., \& Morais, D. (2017). Problem structuring methods in group decision making: a comparative study of their application. Operational Research: An International Journal. https://doi.org/10.1007/s12351-017-0310-0

Davis, F. (1989). Perceived usefulness, perceived ease of use, and user acceptance of information technology. MIS Quarterly, 13(3), 319-340. https://doi.org/10.2307/249008

Eden, C. (2004). Analyzing cognitive maps to help structure issues or problems. European Journal of Operational Research, 159(3), 673-686. https://doi.org/10.1016/S0377-2217(03)00431-4

Eden, C., \& Ackermann, F. (2001). SODA - The principles. In J. Rosenhead \& J. Mingers (Eds.), Rational analysis for a problematic world revisited: problem structuring methods for complexity, uncertainty and conflict. Chichester: John Wiley \& Sons.

Ferreira, F. (2013). Measuring trade-offs among criteria in a balanced scorecard framework: possible contributions from the multiple criteria decision analysis research field. Journal of Business Economics and Management, 14(3), 433-447. https://doi.org/10.3846/16111699.2011.631744

Ferreira, F. (2016). Are you pleased with your neighborhood? A fuzzy cognitive mapping-based approach for measuring residential neighborhood satisfaction in urban communities. International Journal of Strategic Property Management, 20(2), 130-141.

https://doi.org/10.3846/1648715X.2015.1121169

Ferreira, F., \& Jalali, M. (2015). Identifying key determinants of housing sales and time-on-the-market (TOM) using fuzzy cognitive mapping. International Journal of Strategic Property Management, 19(3), 235-244. https://doi.org/10.3846/1648715X.2015.1052587

Ferreira, F., \& Monteiro-Barata, J. (2011). A snapshot of the Portuguese e-banking activity: insights and a conceptual framework to allocate strategic hindrances. International Journal of Electronic Business, 9(3), 238-254. https://doi.org/10.1504/IJEB.2011.042544

Ferreira, F., Ferreira, J., Fernandes, C., Meidutè-Kavaliauskienė, I., \& Jalali, M. (2017). Enhancing knowledge and strategic planning of bank customer loyalty using fuzzy cognitive maps. Technological and Economic Development of Economy, 23(6), 860-876.

https://doi.org/10.3846/20294913.2016.1213200 
Ferreira, F., Jalali, M., \& Ferreira, J. (2016). Integrating qualitative comparative analysis (QCA) and fuzzy cognitive maps (FCM) to enhance the selection of independent variables. Journal of Business Research, 69(4), 1471-1478. https://doi.org/10.1016/j.jbusres.2015.10.127

Ferreira, F., Jalali, M., Ferreira, J., Stankevičienė, J., \& Marques, C. (2016). Understanding the dynamics behind bank branch service quality in Portugal: pursuing a holistic view using fuzzy cognitive mapping. Service Business, 10(3), 469-487. https://doi.org/10.1007/s11628-015-0278-x

Fonseca, M., Ferreira, F., Fang, W., \& Jalali, M. (2018). Classification and selection of tenants in residential real estate: a constructivist approach. International Journal of Strategic Property Management, 22(1), 1-11. https://doi.org/10.3846/ijspm.2018.317

Glykas, M. (2013). Fuzzy cognitive strategic maps in business process performance measurement. Expert Systems with Applications, 40(1), 1-14. https://doi.org/10.1016/j.eswa.2012.01.078

Grandón, E., Nasco, S., \& Mykytyn, P. (2011). Comparing theories to explain e-commerce adoption. Journal of Business Research, 64(3), 292-298. https://doi.org/10.1016/j.jbusres.2009.11.015

Gray, S., Gagnon, A., Gray, S., O’Dwyer, B., O’Mahony, C., Muir, D., Devoy, R., Falaleeva, M., \& Gault, J. (2013). Are coastal managers detecting the problem? Assessing stakeholder perception of climate vulnerability using fuzzy cognitive mapping. Ocean \& Coastal Management, 94, 74-89. https://doi.org/10.1016/j.ocecoaman.2013.11.008

Grillo, C., Ferreira, F., Marques, C., \& Ferreira, J. (2018). A knowledge-based innovation assessment system for small- and medium-sized enterprises: adding value with cognitive mapping and MCDA. Journal of Knowledge Management, 22(3), 696-718. https://doi.org/10.1108/JKM-08-2017-0332

Hester, P. (2015). Analyzing stakeholders using fuzzy cognitive mapping. Procedia Computer Science, 61, 92-97. https://doi.org/10.1016/j.procs.2015.09.159

Kang, B., Deng, Y., Sadiq, R., \& Mahadevan, S. (2012). Evidential cognitive maps. Knowledge-Based Systems, 35, 77-86. https://doi.org/10.1016/j.knosys.2012.04.007

Kim, H., \& Lee, K. (1998). Fuzzy implications of fuzzy cognitive map with emphasis on fuzzy causal relationship and fuzzy partially causal relationship. Fuzzy Sets and Systems, 97(3), 303-313. https://doi.org/10.1016/S0165-0114(96)00349-1

Kok, K. (2009). The potential of fuzzy cognitive maps for semi-quantitative scenario development, with an example from Brazil. Global Environmental Change, 19(1), 122-133. https://doi.org/10.1016/j.gloenvcha.2008.08.003

Kosko, B. (1986). Fuzzy cognitive maps. International Journal of Man-Machine Studies, 24(1), 65-75. https://doi.org/10.1016/S0020-7373(86)80040-2

Koulouriotis, D. (2004). Investment analysis \& decision making in markets using adaptive fuzzy causal relationships. Operational Research: An International Journal, 4(2), 213-233. https://doi.org/10.1007/BF02943610

Lip-Sam, T., \& Hock-Eam, L. (2011). Estimating the determinants of B2B e-commerce adoption among small \& medium enterprises. International Journal of Business and Society, 12(1), 15-30.

MacGregor, R., \& Vrazalic, L. (2006). The effect of small business clusters in prioritising barriers to e-commerce adoption in regional SMEs. Journal of New Business Ideas and Trends, 4(1), 24-44.

Mackenzie, A., Pidd, M., Rooksby, J., Sommerville, I., Warren, I., \& Westcombe, M. (2006). Decision aiding: wisdom, decision support and paradigms of decision making. European Journal of Operational Research, 170(1), 156-171. https://doi.org/10.1016/j.ejor.2004.07.041

Mazlack, L. (2009). Representing causality using fuzzy cognitive maps. In Proceedings of the annual meeting of the north American fuzzy information processing society (NAFIPS-2009), 14-17 June 2009, Cincinnati, Ohio, USA. https://doi.org/10.1109/NAFIPS.2009.5156434

Misthos, L., Messaris, G., Damigos, D., \& Menegaki, M. (2017). Exploring the perceived intrusion of mining into the landscape using the fuzzy cognitive mapping approach. Ecological Engineering, 101, 60-74. https://doi.org/10.1016/j.ecoleng.2017.01.015 
Ngai, E., \& Wat, F. (2002). A literature review and classification of electronic commerce research. Information \& Management, 39(5), 415-429. https://doi.org/10.1016/S0378-7206(01)00107-0

Nisar, T., \& Prabhakar, G. (2017). What factors determine e-satisfaction and consumer spending in e-commerce retailing? Journal of Retailing and Consumer Services, 39, 135-144. https://doi.org/10.1016/j.jretconser.2017.07.010

Organization for Economic Cooperation and Development. (2004). Promoting entrepreneurship and innovative SMEs in a global economy: towards a more responsible and inclusive globalization. In Second OECD Conference of Ministers Responsible for Small and Medium-sized Enterprises (SMEs). Retrieved from https://www.oecd.org/cfe/smes/31919590.pdf

Organization for Economic Cooperation and Development. (2013). Electronic and mobile commerce. OECD Digital Economy Papers, 228, 1-41.

Olazabal, M., Chiabai, A., Foudi, S., \& Neumann, M. (2018). Emergence of new knowledge for climate change adaptation. Environmental Science and Policy, 83, 46-53.

https://doi.org/10.1016/j.envsci.2018.01.017

Olazabal, M., \& Pascual, U. (2016). Use of fuzzy cognitive maps to study urban resilience and transformation. Environmental Innovation and Societal Transitions, 18(1), 18-40. https://doi.org/10.1016/j.eist.2015.06.006

Özesmi, U., \& Özesmi, S. (2004). Ecological models based on people’s knowledge: a multi-step fuzzy cognitive mapping approach. Ecological Modelling, 176(1/2), 43-64. https://doi.org/10.1016/j.ecolmodel.2003.10.027

Pinto, S., \& Ferreira, F. (2010). Technological dissemination in the Portuguese payments system: an empirical analysis to the region of Santarém. International Journal of Human Capital and Information Technology Professionals, 1(4), 55-75. https://doi.org/10.4018/jhcitp.2010100104

Pires, A., Ferreira, F., Jalali, M., \& Chang, H.-C. (2018). Barriers to real estate investments for residential rental purposes: mapping out the problem. International Journal of Strategic Property Management, 22(3), 168-178. https://doi.org/10.3846/ijspm.2018.1541

Rahayu, R., \& Day, J. (2015). Determinant factors of e-commerce adoption by SME in developing country: evidence from Indonesia. Procedia - Social and Behavioral Sciences, 195, 142-150. https://doi.org/10.1016/j.sbspro.2015.06.423

Ramos, J., Ferreira, F., \& Monteiro-Barata, J. (2011). Banking services in Portugal: a preliminary analysis to the perception and expectations of front office employees. International Journal of Management and Enterprise Development, 10(2/3), 188-207. https://doi.org/10.1504/IJMED.2011.041549

Reis, J., Ferreira, F., \& Monteiro-Barata, J. (2013). Technological innovation in banking services: an exploratory analysis to perceptions of the front office employee. Problems and Perspectives in Management, 11(1), 34-49.

Ribeiro, M., Ferreira, F., Jalali, M., \& Meidute-Kavaliauskienè, I. (2017). A fuzzy knowledge-based framework for risk assessment of residential real estate investments. Technological and Economic Development of Economy, 23(1), 140-156. https://doi.org/10.3846/20294913.2016.1212742

Salmeron, J. (2012). Fuzzy cognitive maps for artificial emotions forecasting. Applied Soft Computing, 12(12), 3704-3710. https://doi.org/10.1016/j.asoc.2012.01.015

Savrul, M., Incekara, A., \& Sener, S. (2014). The potential of e-commerce for SMEs in a globalizing business environment. Procedia - Social and Behavioral Sciences, 150(15), 35-45. https://doi.org/10.1016/j.sbspro.2014.09.005

Seyal, A., \& Rahman, M. (2003). A preliminary investigation of e-commerce adoption in small \& medium enterprises in Brunei. Journal of Global Information Technology Management, 6(2), 6-26. https://doi.org/10.1080/1097198X.2003.10856347 
Sila, I. (2013). Factors affecting the adoption of B2B e-commerce technologies. Electronic Commerce Research, 13(2), 199-236. https://doi.org/10.1007/s10660-013-9110-7

Sin, K., Osman, A., Salahuddin, S., Abdullah, S., Lim, Y., \& Sim, C. (2016). Relative advantage and competitive pressure towards implementation of e-commerce: overview of small and medium enterprises (SMEs). Procedia - Economics and Finance, 35, 434-443. https://doi.org/10.1016/S2212-5671(16)00054-X

Stylios, C., \& Groumpos, P. (1998). The challenge of modelling supervisory systems using fuzzy cognitive maps. Journal of Intelligent Manufacturing, 9(4), 339-345. https://doi.org/10.1023/A:1008978809938

Sutanonpaiboon, J., \& Pearson, A. (2006). E-commerce adoption: perceptions of managers/owners of small- and medium-sized enterprises (SMEs) in Thailand. Journal of Internet Commerce, 5(3), 5382. https://doi.org/10.1300/J179v05n03_03

Tegarden, D., \& Sheetz, S. (2003). Group cognitive mapping: a methodology and system for capturing and evaluating managerial and organizational cognition. Omega - The International Journal of Management Science, 31(2), 113-125. https://doi.org/10.1016/S0305-0483(03)00018-5

Tolman, E. (1948). Cognitive maps in rats and men. The Psychological Review, 55(4), 189-208. https://doi.org/10.1037/h0061626

Tsadiras, A. (2008). Comparing the inference capabilities of binary, trivalent and sigmoid fuzzy cognitive maps. Information Sciences, 178(20), 3880-3894. https://doi.org/10.1016/j.ins.2008.05.015

Turban, E., Lee, J., King, D., McKay, J., \& Marshall, P. (2008). Electronic commerce 2008: a managerial perspective. Upper Saddle River: Prentice Hall.

Vajjhala, N., \& Thandekkattu, S. (2017). Potential and barriers to adoption of B2B e-commerce in SMES in transition economies: case of Albania. Management, 12(2), 155-169. https://doi.org/10.26493/1854-4231.12.155-169

Venkatesh, V., Morris, M., Davis, G., \& Davis, F. (2003). User acceptance of information technology: toward a unified view. MIS Quarterly, 27(3), 425-478. https://doi.org/10.2307/30036540

Vidal, R. (2004). Guest editor's introduction. European Journal of Operational Research, 152(3), 529. https://doi.org/10.1016/S0377-2217(03)00055-9

Walker, J., Saffu, K., \& Mazurek, M. (2016). An empirical study of factors influencing e-commerce adoption/non-adoption in Slovakian SMEs. Journal of Internet Commerce, 15(3), 189-213. https://doi.org/10.1080/15332861.2016.1191049

Wisen, F., Mey, Y., Lauwers, L., Passel, S., Vancauteren, M., \& Wauters, E. (2013). Cognitive mapping: a method to elucidate and present farmers' risk perception. Agricultural Systems, 122, 42-52. https://doi.org/10.1016/j.agsy.2013.08.003

Yaman, D., \& Polat, S. (2009). A fuzzy cognitive map approach for effect-based operations: an illustrative case. Information Sciences, 179(4), 382-403. https://doi.org/10.1016/j.ins.2008.10.013

Zavadskas, E., \& Turskis, Z. (2011). Multiple criteria decision making (MCDM) methods in economics: an overview. Technological and Economic Development of Economy, 17(2), 397-427. https://doi.org/10.3846/20294913.2011.593291

Zhang, C., \& Dhaliwal, J. (2009). An investigation of resource-based and institutional theoretic factors in technology adoption for operations and supply chain management. International Journal of Production Economics, 120(1), 252-269. https://doi.org/10.1016/j.ijpe.2008.07.023 